\title{
The Past Explains the Present
}

BAMS spoke with author Sarah Dry about her book Waters of the World: The Story of the Scientists Who Unraveled the Mysteries of Our Oceans, Atmosphere, and Ice Sheets and Made the Planet Whole (2019, University of Chicago Press). A writer and historian of science, Dry is also the author of The Newton Papers: The Strange and True Odyssey of Isaac Newton's Manuscripts. Born and raised in Philadelphia, she is spending the year at the Institute for Advanced Study in Princeton, New Jersey, with her family, and is on the board of the Science Museum Group in the United Kingdom.

\section{Why write this book?}

Climate change is the key challenge of our time, but there's surprisingly little on the history of our understanding of climate. I wanted to write something that would extend the timeline of that understanding further in the past than is usually the case. Rather than beginning in the postwar period or, even more recently, with the burgeoning environmental consciousness of the 1960s and 1970s, I wanted to show how scientists have been studying Earth's climate for a long time. I chose the mid-nineteenth century as my starting point, as the discovery of the ice ages plunged Victorians into a reckoning with dramatic and relatively recent climatic change. In that sense, it's a useful analogue for our present moment, especially since it turns our assumptions upside down. The Victorians were shocked that the Earth might have been colder in the past, while we fear the Earth getting warmer in the future.

\section{Who is the book for?}

Anyone who cares about the planet and wants to gain a better understanding of the relationship between individual scientists working at particular times and in particular places and the knowledge of the climate we now call global.

\section{What obstacles did you face writing this book?}

In trying to create a more expansive history of our understanding of the climate, I crossed a lot of disciplinary boundaries and a lot of time periods. That meant I had to improve my understanding of the history of many aspects of what is today climate science, including meteorology, atmospheric physics, climatology, ice physics, glaciology, geology, oceanography, and computer science. That is a lot! Depending on how I felt on a given day, this was an exciting or somewhat ridiculous proposition. I also worked hard to find individual scientists who ticked

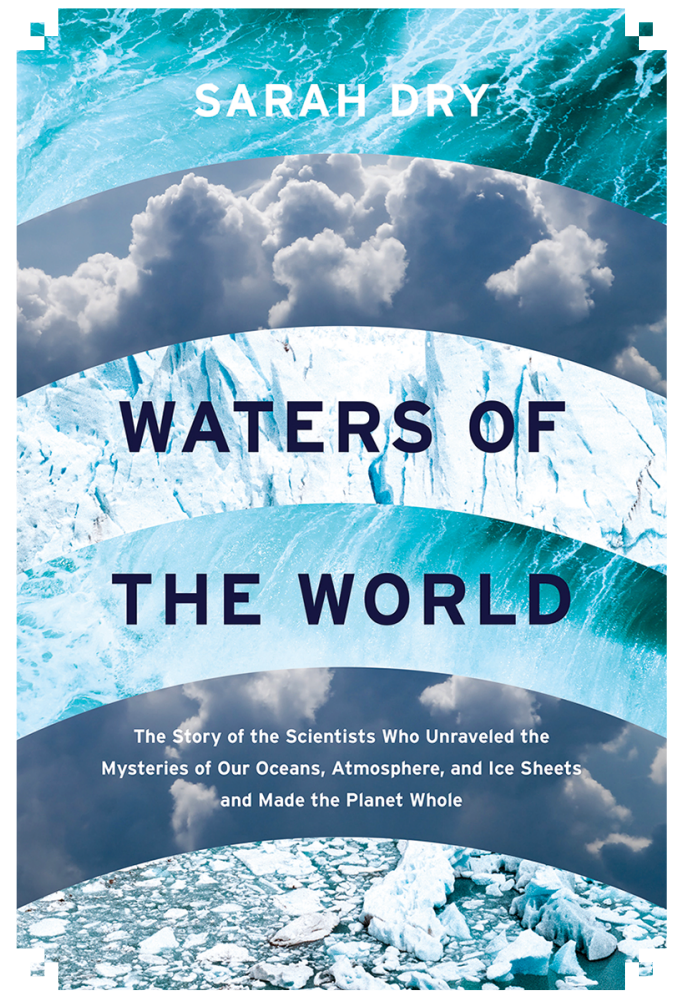
all the right boxes: they needed to have led fascinating lives, done important work in the field, and left good manuscript records behind. It took a while to assemble the right dream team for my purposes.

\section{What did you learn?}

Just how important observation is to the history of climate knowledge. Given my biographical focus, I was able to see just how formative the act of observing water in climate was for my protagonists-from John Tyndall's work measuring glaciers and ice, to Charles Piazzi Smyth's lifetime of drawing, painting, and photographing clouds and 
other meteorological phenomena, to Joanne Simpson's detailed studies of individual clouds based on photographs taken from instrumented aircraft. Even Henry Stommel, a great theoretical oceanographer, was constantly seeking new observations with which to test his theories. He was, by his own admission, an awkward shipboard presence but he nevertheless made many ocean voyages precisely because he wanted to get as close to the act of observation as possible.

\title{
What are the implications of this work?
}

That to understand how climate science works today, we need to understand its history. That history, as I've tried to show, is multidisciplinary-it's rooted in a bunch of different subdisciplines that have only relatively recently been

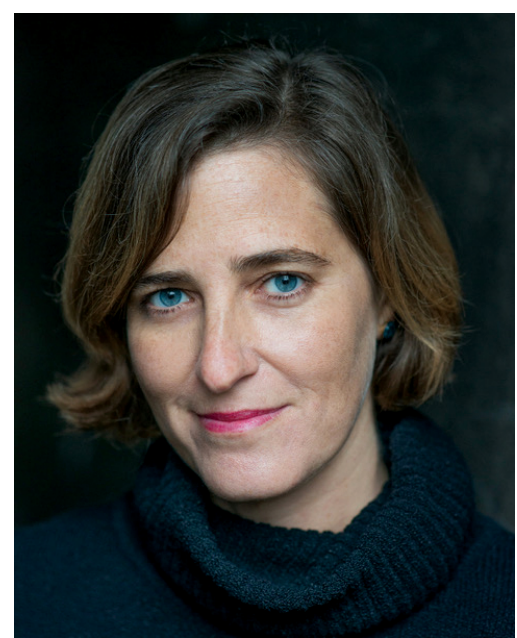

Sarah Dry [Photo credit: David Myers] united under the mantle of climate science. This many-stranded history has left its traces in our current science. It affects how we rank different kinds of evidence about climate-from paleoclimatic proxy data such as ice and mud cores to instrumental records of temperature to computer models that allow scientists to test theories about the climate system and create simulations of future climate. Understanding how climate science functions today depends on understanding the history of how we rate different types of evidence. At the same time, I hope my book can remind people just how robust our knowledge of the planet is. People have been studying the Earth for a long time and we've gotten to be pretty good at it. The dedication, the passion, and the sheer talent of the people I write about never fail to inspire me.

\section{Do you have any plans for other books?}

My new project picks up where Waters of the World left offin the 1960s and 1970s when climate science emerges as an interdisciplinary science. I'm looking forward to giving more attention to the relationship between science and policy and thinking about how new disciplines actually form. This means looking at key conferences that brought together people from different fields interested in better understanding both the nature of the global climate system and how humans were affecting it. One interesting fact is that the discovery of anthropogenic climate change occurred at pretty much the same time that scientists found evidence for abrupt climatic change in the past. One of the first problems that faced these scientists was how to distinguish natural versus anthropogenic change-a problem that is still with us today.

\author{
I hope my book can remind people just how robust our knowl- \\ edge of the planet is. People have been studying the Earth \\ for a long time and we've gotten to be pretty good at it. The \\ dedication, the passion, and the sheer talent of the people I \\ write about never fail to inspire me.
}




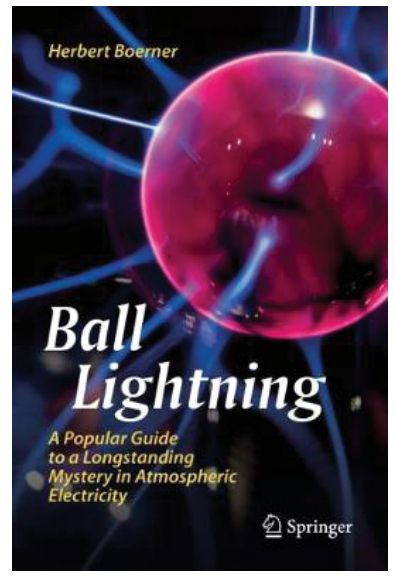

Ball Lightning: A Popular Guide to a Longstanding Mystery in Atmospheric Electricity, by Herbert Boerner 2019, 205 pp., \$23.00, hardbound, Springer, ISBN 978-3030207823

Despite several thousand reported observations, the nature of ball lightning is still unknown. In this book, documented cases of the phenomenon are described and used to unravel some aspects of this mysterious form of atmospheric electricity. The author, a Ph.D. in high energy physics who has worked on the physics and engineering of organic light-emitting diodes, discusses the various facets of ball lightning. The text includes a foreword by Earle Williams, leading lightning researcher at the Massachusetts Institute of Technology.
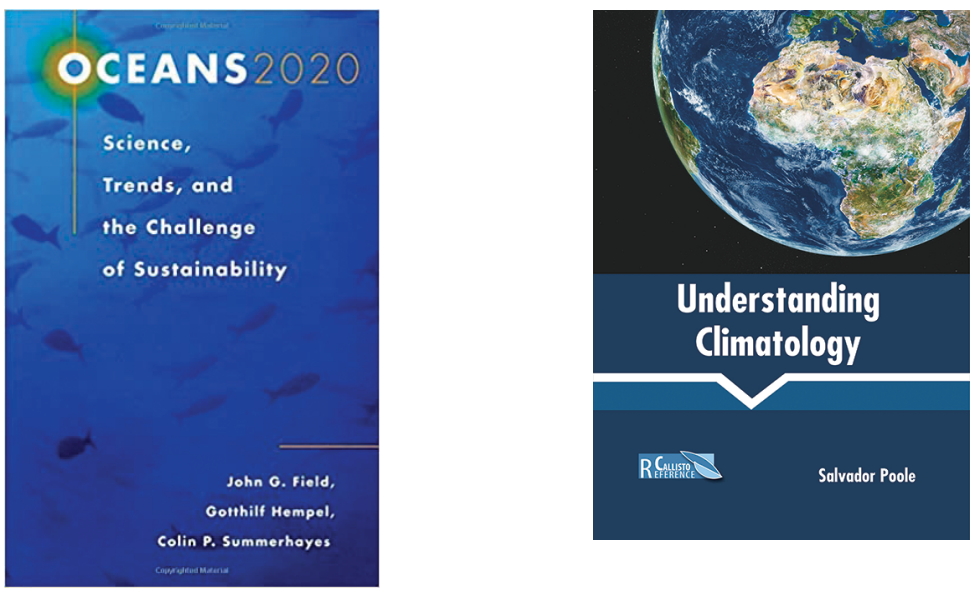

Oceans 2020: Science, Trends, and the Challenge of Sustainability, by John G. Field, Gotthilf Hempel, and Colin P. Summerhayes

2020, 384 pp., \$39.00, softbound, Island Press, ISBN 978-1559634700

Oceans 2020 presents an assessment of scientific and societal issues that are likely to arise in marine science and ocean management in the next 20 years. Sponsored by the Intergovernmental Oceanographic Commission (IOC), the Scientific Committee on Oceanic Research (SCOR), and the Scientific Committee on Problems of the Environment (SCOPE), the book brings together ocean scientists and researchers to analyze the state of marine science and technology, identify key scientific issues for sustainable development, and evaluate the capability of scientists, governments, and private sector stakeholders to respond to those issues.
Understanding Climatology, by Salvador Poole 2019, 264 pp., \$160.00, hardbound, Callisto Reference, ISBN 978-1641162388 Various climate models that are based on mathematical formulations of past, present, and future climates are proposed for the study of climates. This textbook is a compilation of topics, ranging from the basic to the most complex theories and principles in the field of climatology. It aims to shed light on some of the unexplored aspects of climatology, and can serve as a resource guide for students and experts alike to help contribute to the growth of the discipline. 


\section{AMS Publications introduces}

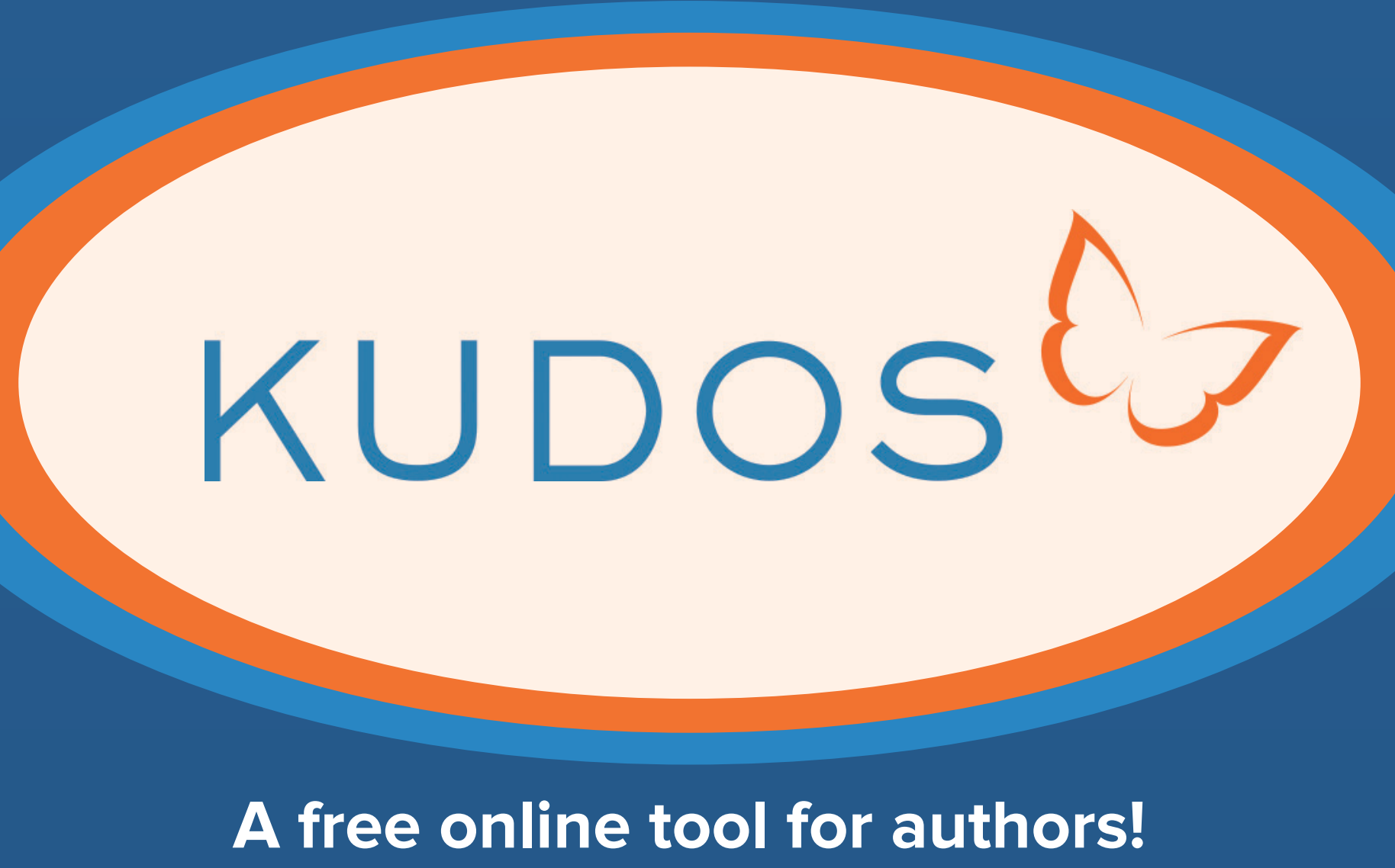

Communicate Your Research More Effectively

\section{Increase Your Work's Impact}

- Maximize citations and downloads of your article

- Open up your research to new audiences

- Explain and share your work in only 10 minutes

- Increase full-text article downloads by $23 \%$

- Access publication metrics via the author dashboard

Learn more about using Kudos with AMS

https://www.ametsoc.org/kudos/ 